\title{
Enfoque de la autonomía local en los sistemas alemán y británico de financiación municipal
}

\section{Approach to local autonomy in the German and British systems of municipal financing}

\author{
Francisco Javier Durán García \\ Universidad Pontificia Comillas \\ fcojavierdg@gmail.com
}

\begin{abstract}
RESUMEN
En el ámbito europeo el reconocimiento de la autonomía local es una cuestión pacífica tras aprobarse en la Carta Europea de la Autonomía Local. No obstante, el alcance que tiene esta autonomía local en materia financiera varía en función del modelo de hacienda pública que adopta cada país. En el presente trabajo analizamos los modelos alemán y británico de hacienda local, dos ejemplos opuestos en la forma de organizar su hacienda que inciden de manera directa sobre el alcance de la autonomía local de sus municipios. Tras una primera parte donde se analiza la base jurídica de la autonomía local, se procede al estudio de las principales fuentes de financiación municipal en cada modelo, y se concluye con una valoración de la autonomía financiera de las entidades locales dentro del sistema español en comparación con los modelos expuestos.
\end{abstract}

\section{PALABRAS CLAVE}

Autonomía local, hacienda pública, Alemania, Reino Unido, financiación local.

\begin{abstract}
At the European level the recognition of local self-government is a peaceful matter after being approved in the European Charter of Local Autonomy. However, the scope of this local financial autonomy varies according to the model of public finances that each country adopts. In this article we analyze the German and British models of local finance, two opposite examples in the way of organizing their treasure that directly affect the scope of the local autonomy of their municipalities. After a first part where the legal basis of the local autonomy is analyzed, the main sources of municipal financing are studied in each model, and it concludes with an assessment of the financial autonomy of the local entities within the Spanish system in comparison with the exposed models.
\end{abstract}

\section{KEY WORDS}

Local autonomy, public finance, Germany, United Kingdom, local financing.

\section{ÍNDICE}

1. INTRODUCCIÓN. 2. LA REALIDAD UTÓPICA DE LA AUTONOMÍA FINANCIERA. 3. FINANCIACIÓN LOCAL EN ALEMANIA. 3.1. EL MODELO FEDERAL. 3.2. FUENTES DE INGRESOS LOCALES. 4. FINANCIACIÓN LOCAL EN REINO UNIDO. 4.1. EL MODELO ANGLOSAJÓN Y LAS TRANSFERENCIAS. 4.2. FUENTES DE INGRESOS LOCALES. 5. VALORACIÓN A LA LUZ DEL SISTEMA ESPAÑOL. 6. BIBLIOGRAFÍA. 


\section{INTRODUCCIÓN}

Cualquier estudio que propiciemos sobre la realidad de la Administración local implica necesariamente un acercamiento al sistema de financiación municipal. Tal es así, que en todas las entidades de organización local, independientemente del grado de descentralización que han ido desarrollando en el margen otorgado dentro de sus propios sistemas políticos, se tiene entre las prioridades dotar a la estructura local de recursos propios para intentar cubrir sus necesidades competenciales.

Si por algo se caracteriza el Municipio es por ser la estructura política más próxima al ciudadano. Esta circunstancia determina, en gran medida, la categoría de las manifestaciones tributarias locales ya que la gestión y la recaudación de muchos de los tributos sólo tienen su eficacia en un contexto de proximidad. En el mismo sentido, el resto de recursos que conforman la totalidad de la Hacienda municipal también reciben un tratamiento singular desde la óptica de la cercanía, en tanto que son destinatarios de los recursos los propios ciudadanos de los que han salido.

Es innegable la importancia de la financiación, y más concretamente la relevancia de los tributos en sus diferentes acepciones, para el desarrollo de la Administración. Tal es así, que la filosofía que inspira el sistema político de un país, atrae y determina la condición de su Hacienda, siendo esta herramienta un fiel reflejo en el tiempo de las premisas que han marcado y marcan la evolución del pensamiento político y social. Por esta razón, entendemos acertado un estudio comparativo de sistemas que comparten una misma base de principios, en tanto que nos permite confrontar las diferentes soluciones que se han dado con motivo de problemas comunes en el ámbito municipal de los diferentes países. Así, más allá de las categorías y definiciones particulares que se han creado por cada sistema jurídico particular, queda buscar la intuición común en los distintos legisladores a la hora de determinar el problema y buscar la solución.

Un marco correcto para confrontar sistemas es Europa por ser un ámbito donde concurren sistemas de tradición jurídica distinta pero donde el Municipio se enfrenta a retos similares a nivel competencial y, consecuentemente, en materia de financiación. Es más, si observamos el amplio espectro que abarcan y la incidencia sobre la ciudadanía, el conocimiento de los diferentes sistemas impositivos no sólo es interesante sino también de obligado conocimiento para el ciudadano o ciudadana que puede quedar afecto a su observancia tanto en su país de origen como en otro país donde resida temporalmente o por simple turismo (Vg.: tasas por estacionamiento limitado de vehículos en dominio público, precios públicos para acceder a instalaciones y monumentos, impuestos «ecológicos» y similares).

En definitiva, al cotejar autonomía local y fuentes de financiación, no sólo queremos analizar realidades impositivas sino también propiciar el acercamiento a los problemas actuales que presenta la Hacienda local en diferentes países. Analizando las preferencias o directrices que se siguen en cada Estado podremos atisbar lo común y lo diferente, las carencias y los aciertos en la concreción que cada sistema municipal ha realizado.

\section{LA REALIDAD UTÓPICA DE LA AUTONOMÍA FINANCIERA}

Los Estados miembros del Consejo de Europa establecieron el 15 de octubre de 1985 la Carta Europea de Autonomía Local ${ }^{1}$. Este texto común recoge en su art. 9 el derecho de las Entidades locales, proporcionalmente y en el marco de la política económica nacional, a tener recursos propios suficientes de los cuales pueden disponer libremente en el ejercicio de sus competencias. Es más, en cada uno de sus apartados concreta las características de dicha financiación: ingresos patrimoniales y tributos locales; sistema diversificado que permita la evolución real de los costes; procedimientos de compensación financiera destinados a corregir las desigualdades; las subvenciones evitaran ser finalistas para no coaccionar la política local; y posibilidad de acceso al mercado nacional de valores.

A la vista del anterior documento, queda claro que el marco fundamental y las directrices están ya establecidas para los municipios en el ámbito territorial europeo. En concreto, los países cuyo sistema analizamos, tienen en común que han ratificado este documento y, por lo tanto, comparten las premisas establecidas en la Carta de la Autonomía Local. Bien es cierto que los sistemas de financiación municipal de los diferentes Estados son anteriores a la Carta, y por esta razón es interesante como punto de partida en

1 Instrumento de Ratificación, de 20 de enero de 1988, de la Carta Europea de 15 de octubre de 1985 de Autonomía Local, hecha en Estrasburgo. 
tanto que el texto en si es un ejemplo patente de derecho comparado por cuanto se construyó a partir de los puntos en común y las sinergias que presentan los municipios en Europa.

Ahora bien, el texto del Consejo para su aplicación no sólo depende de la ratificación sino también del grado de concreción que vaya realizando cada país. En este sentido, vemos como no uniforma ordenamientos sino que los acerca conjugando la integración y el respeto a la diversidad, más patente si cabe en el ámbito local por cuanto es el más permeable a la cultura propia. Es más, aunque la autonomía local está proclamada, ya adelantamos que en los sistemas que analizamos a continuación todavía dista mucho de ser efectiva en tanto que la realidad marca una gran dependencia frente a otros niveles de la Administración.

\section{FINANCIACIÓN LOCAL EN ALEMANIA}

\subsection{EL MODELO FEDERAL}

La estructura de las diferentes haciendas locales ha sido estudiada por SUÁREZ PANDIELLO², quien establece una clasificación de los sistemas atendiendo a la figura o figuras que soportan el peso. Para el caso de Alemania la financiación local se categoriza en el modelo federal que comparte con Austria y Bélgica. La característica principal de este modelo es la combinación de las fuentes de financiación de los modelos insular y nórdico en tanto que el centro de gravedad se distribuye en la imposición sobre los bienes inmuebles y en la tributación sobre la renta individual. En concreto, Alemania incide más en la renta de las personas hasta el punto de alcanzar un promedio del $40 \%$ sobre el total de la financiación ${ }^{3}$.

Como podemos apreciar, el sistema de financiación municipal alemán está centrado en los ingresos con origen impositivo. A este tenor, es en la Ley Fundamental de Bonn donde se establecen los impuestos de los que se valdrá un Municipio atendiendo a la competencia sobre el rendimiento, a saber: por una parte los impuestos propios (Gemeindesteuern) y por otra los impuestos compartidos con los otros niveles territoriales (Gemeinschaftsteuern).

A más abundamiento, cabe señalar que la autonomía financiera local está recogida de manera expresa en el art. 28.2 de la Constitución alemana como parte de la autonomía local, y como base del derecho de los municipios a establecer tipos impositivos cuya naturaleza se encuentre en el ámbito local. No obstante lo anterior, la competencia tributaria de los entes locales en Alemania tiene un carácter derivado ya que sólo pueden crear impuestos cuando la entidad territorial superior, los Länder, hayan delegado expresamente, y sólo para los impuestos sobre el consumo o el gasto en la circunscripción local ${ }^{4}$.

\subsection{FUENTES DE INGRESOS LOCALES}

A continuación, de manera sucinta, analizaremos las distintas fuentes de financiación que componen la Hacienda local alemana destacando las características más relevantes de cada uno de los tributos e ingresos.

\section{A) IMPUESTOS PROPIOS}

Como hemos apuntado en el apartado anterior, la competencia sobre el rendimiento del Impuesto sobre Bienes Inmuebles (Grundsteuer) y el Impuesto sobre Actividades Económicas (Gewerbesteuer) queda establecida por la Constitución a favor de los municipios. No obstante lo anterior, la competencia normativa sobre estos impuestos corresponde a la Federación (Bund), si bien los municipios tienen atribuido constitucionalmente el derecho a establecer los tipos de gravamen (art. 106.6) a través de una ordenanza fiscal municipal en virtud de un porcentaje sobre el líquido imponible, pero dentro de los márgenes que los Länder establezcan.

Respecto de la competencia de gestión o administrativa cabe reconocer una gestión compartida entre los Länder, quien en virtud del art. 108 de su Constitución determina la base imponible (valor del bien en cuestión y su atribución), y entre los municipios, cuya administración se encargará de dictar el correspon-

2 SUÁREZ PANDIELLO (2008): 238-240.

3 Para profundizar sobre los datos, nos remitimos al estudio de Ángel DE LA FUENTE: "La financiación regional en Alemania y en España: Una perspectiva comparada", Fedea Policy Papers, 2017/01.

4 GARCÍA FRÍAS (2005): 35. 
diente acto de liquidación del impuesto. Vistas las competencias analizaremos la configuración de los impuestos propios.

\section{A1. Impuesto sobre Bienes Inmuebles (Grundsteuer)}

EI IBI es una pieza importante dentro de la Hacienda municipal alemana, hecho que actualmente lo hace irrenunciable para este nivel de la administración en tanto que no han surgido todavía otros recursos que lo puedan sustituir. Una característica que lo diferencia del IAE es su estabilidad recaudatoria dado que su cuantía anual es previsible porque no depende de las incidencias económicas y no incide colateralmente sobre la competencia de las empresas a nivel internacional.

Nos encontramos ante un tributo cuya territorialización se determina según la ubicación del inmueble objeto de gravamen, y por lo tanto no existen problemas de traslación de la carga impositiva fuera del ente local en el que tributa. Dicho impuesto se justifica bajo el principio de equivalencia entre gastos e ingresos públicos dado que el Municipio que recibe el tributo es el que soporta los gastos en concepto de dotación de infraestructuras y bienes públicos que benefician directa o indirectamente a los propietarios de los bienes inmuebles ubicados en el término municipal.

En otro orden de cosas, este impuesto supone un alto grado de corresponsabilidad fiscal para los responsables municipales puesto que el importe de la recaudación dependerá de la presión fiscal que establezcan a la hora de determinar los tipos de gravamen a través de la ordenanza municipal correspondiente. Por lo tanto, el carácter local de este tributo es patente por cuanto la política local asume los costes o beneficios de su decisión sobre el tipo de gravamen, y los ciudadanos distinguen claramente el origen y el destino municipal de su contribución, así como su destino correcto o su mal uso.

Las ideas anteriores, tomadas del estudio realizado por el Instituto de Estudios Autonómicos de la Generalitat de Catalunya sobre Gobiernos locales en Estados federales y descentralizados, muestran que el IBI en Alemania supone una clara manifestación de la autonomía local. No obstante, dicha importancia queda relativizada desde la comparación internacional, según se desprende del citado trabajo:

«la parte que la recaudación del IBI representa en el conjunto de los ingresos impositivos de los municipios en Alemania está claramente por debajo del nivel de otros Estados europeos. Así, en el periodo comprendido entre los años 1965-2000, mientras que la recaudación de los impuestos ligados al patrimonio representa respecto al conjunto de los ingresos impositivos de los municipios el 99,7\% en Gran Bretaña, el 51,6\% en Francia, el 35,5\% en España y el 21,7\% en Italia, en Alemania se situó en el $15 \%^{5}$.»

\section{A2. Impuesto sobre Actividades Económicas (Gewerbesteuer)}

La versión original de la ley reguladora de este impuesto es del 1 de diciembre de 1936, en la misma el tributo se establecía en virtud de tres elementos de la estructura empresarial: la suma total de los salarios pagados, el patrimonio de la industria, y el beneficio empresarial. No obstante, en la última versión de la ley reguladora de este impuesto, con fecha de publicación 15 de octubre de 2002 en el Boletín Oficial de la Federación, han sido derogadas las partes del impuesto referentes al capital y a los salarios, y el IAE sólo se recauda en virtud del beneficio empresarial.

Sobre la recaudación de este impuesto cabe también señalar que, aunque la competencia sobre el impuesto es municipal, tras la entrada de los municipios en la participación en el IRPF se estableció la obligación de reintegrar una cuota a las instancias superiores a modo de compensación, y por lo tanto debe distinguirse una recaudación bruta y una recaudación neta tras la satisfacción de las meritadas cuotas.

Al igual que el IBI, este impuesto ostenta una posición principal en la financiación local alemana como fuente de ingresos y capacidad del Municipio para regular el tipo de gravamen en términos similares al IBI. El citado estudio de la Generalitat de Catalunya aporta datos que destacan el crecimiento del peso de este impuesto en el conjunto de ingresos del municipios a medida que éste es más grande en número de habitantes ${ }^{6}$.

\footnotetext{
5 VELASCO CABALLERO (2010): 153.

6 VELASCO CABALLERO (2010): 156.
} 


\section{A3. Impuestos sobre el consumo y el gasto local (Örtkiche Verbrauch- und Auf-wandsteuern)}

Los Länder pueden delegar en los municipios la competencia para establecer este tipo de impuestos bajo dos condiciones. En primer lugar, que no existan tributos equivalentes regulados por la Federación, y, en segundo lugar, que el consumo o gasto se produzca en el ámbito del Municipio.

La casuística es amplia y dependerá en gran medida en la discrecionalidad que otorgue el Länd, y de las facultades que desarrolle el Municipio plasmando el impuesto en una ordenanza reguladora y asumiendo la gestión de la recaudación. Sin embargo, la competencia actual en la mayoría de los municipios se ciñe en la práctica a la implementación de tres impuestos: a) el impuesto sobre la tenencia de perros (Hundsteuer) con la doble finalidad de recaudar y de incentivar la limitación al número de animales; b) el impuesto sobre las diversiones (Vergnügungsteuer), especialmente sobre las máquinas automáticas; y c) el impuesto a la segunda vivienda (Zweiwohnungsteuer) con la finalidad de hacer tributar a las personas que no computan a efectos del IRPF por no estar empadronados y que, sin embargo, disponen de una segunda vivienda en ese Municipio.

La principal virtud de este tipo de impuestos es que sintetizan a la perfección la autonomía local en tanto que son tributos creados y diseñados por los propios municipios siempre y cuando respeten el principio de no equivalencia ${ }^{7}$.

\section{B) IMPUESTOS COMPARTIDOS}

El otro pilar fundamental de la financiación local en Alemania recae sobre los impuestos comunes: el Impuesto sobre la Renta, que engloba también el denominado impuesto sobre el salario (Lohnsteuer), y el IVA. Así se dispuso tras la reforma del sistema de financiación local realizada en el año 1969 con la aprobación de la Ley de Reforma Financiera Municipal, desde entonces hasta la fecha participan de manera compartida en la recaudación de estos impuestos las tres administraciones territoriales: la Federación (Bund), los Estados federados (Länder) y los municipios (Gemeinden) $)^{8}$. Pasamos a exponer los aspectos más relevantes de cara a nuestra comparativa.

\section{B1. Impuesto sobre la Renta (Einkommensteuer)}

Antes de existir la participación municipal en el IRPF, la economía local dependía en gran medida de la recaudación conseguida a través del IAE, esta situación traía dos problemas: inestabilidad ante un impuesto dependiente de la situación económica y disparidades en la recaudación entre los diferentes municipios que disponían de un número de empresas variable. Ante esta situación, se acordó la participación en este impuesto con el fin de aumentar la recaudación y dar estabilidad al sistema de recursos impositivos en las haciendas locales; no obstante, en contraprestación, como ya comentamos, se estableció una cuota a favor del Bund y del Länder en el IAE que recauda el Municipio.

A grandes rasgos, el reparto de la participación en el IRPF se hace en virtud de dos criterios: el número de contribuyentes que tengan su residencia habitual o su domicilio en el Municipio, y el grado de contribución que por el impuesto realiza cada uno de ellos. Respecto del rendimiento total que el impuesto proporciona al Länd, al Municipio le corresponde el $15 \%$ de la recaudación sobre el salario y sobre la renta liquidable, y el $12 \%$ de las retenciones sobre los intereses, y al Bund y al Länd el resto de la recaudación a partes iguales. Aunque estos criterios de distribución de recursos son más uniformes que los del IAE, también se acompaña esta participación de un mecanismo de nivelación que compensa las desigualdades que se produzcan con el reparto entre los municipios (especialmente con los del este) mediante el establecimiento de unos límites máximos de renta gravada tanto para la tributación individual como para la conjunta.

EI Prof. GARCÍA MARTíNEZ ${ }^{9}$ señala en su estudio sobre este impuesto que la participación de los municipios equivale materialmente a una transferencia y que, consecuentemente, supone un claro déficit de autonomía tributaria local en tanto que cualquier decisión de bajada de impuestos del Estado federal presume una reducción de los ingresos sin que los municipios puedan decidir al respecto. Aunque esta ausencia de corresponsabilidad fiscal, que ensombrece la percepción de los contribuyentes sobre su contribución a

\footnotetext{
VELASCO CABALLERO (2010): 160.

GARCÍA MARTÍNEZ (2009): 348.

GARCÍA MARTÍNEZ (2009): 376.
} 
la financiación municipal, ha llevado al Gobierno a plantearse la sustitución de esta participación por un auténtico tramo municipal del impuesto, a día de hoy no se ha modificado porque este cambio supondría una evidente pérdida de solidad financiera intermunicipal, que preferentemente hay que preservar.

\section{B2. IVA}

Al igual que la participación municipal en el IRPF, la intervención en la recaudación obtenida por el IVA tiene como fin cubrir las carencias financieras ocasionadas en la Hacienda municipal alemana con motivo de las derogaciones y bajadas que se han practicado al IAE.

Del mismo modo que en el impuesto anterior, exponemos de manera resumida los aspectos más destacados del mecanismo de este tributo. El cálculo del impuesto se realiza sobre la base del importe de recaudación del IVA minorada en un descuento previo a favor del Bund (con destino a las coberturas de las pensiones de los trabajadores que ofrece la Seguridad Social); una vez minorada la base se aplica el $2,2 \%$ de porcentaje que le corresponde a la participación municipal, y el resto se repartirá entre el Bund y los Länder a través de los mecanismos de compensación establecidos por la ley. El porcentaje municipal se repartirá entre los diferentes municipios del Länd en función de los coeficientes que determine el Gobierno.

Al valorar este impuesto, estamos de acuerdo con VELASCO ${ }^{10}$ al señalar que supone una participación muy estable para la Hacienda local, y que la importancia de este recurso aumenta a medida que es mayor el número de habitantes. También, al igual que en el caso del IRPF, debemos destacar la regresión que supone esta participación desde la óptica de la autonomía tributaria, no sólo porque el Municipio adolece de la potestad de fijar tipos sino también porque también desaparece la corresponsabilidad a expensas de las decisiones del Gobierno central. Nuevamente se ven abocados al enfrentamiento dos principios básicos, por una parte la estabilidad financiera y por otra la autonomía local, en este caso se opta por la primera.

\section{C) OTRO TRIBUTOS}

A parte de los tributos de naturaleza impositiva, también forman parte de la Hacienda local las tasas y las contribuciones especiales. Las tasas pueden tener su origen en cada uno de los entes territoriales, siendo las de origen municipal las únicas cuyo establecimiento queda a discreción del Municipio. Las contribuciones especiales, al igual que en España, tienen como fin cubrir el coste de servicios creados por el Municipio. El porcentaje de estos tributos frente a lo recaudado por los impuestos es muy discreto.

\section{D) LA COMPENSACIÓN FINANCIERA}

Finalmente, haremos referencia a un grupo de ingresos con origen en los recursos del Länd y que tienen la finalidad de compensar los desequilibrios territoriales. A través de este mecanismo, las debilidades financieras de los municipios quedan resueltas con el fin de que conseguir cierta igualdad en los servicios que se prestan en todos ellos. Estos ingresos no son financieros y por lo tanto la autonomía local no está presente en este tipo de subvenciones.

\section{FINANCIACIÓN LOCAL EN REINO UNIDO}

\subsection{EL MODELO ANGLOSAJÓN Y LAS TRANSFERENCIAS}

Siguiendo la estructura adoptada por SUÁREZ PANDIELLO ${ }^{11}$, el sistema tributario de los municipios en el Reino Unido se encuadra en el denominado modelo anglosajón. En esta categoría insular quedaría también agrupado el sistema de Irlanda, ya que ambos se caracterizan por basar todo el peso de la imposición local en el impuesto sobre la propiedad inmobiliaria. Ahora bien, salvo este tributo, los municipios británicos carecen de un sistema de recursos propios que sufraguen la mayor parte del gasto público.

10 VELASCO CABALLERO (2010): 185 y ss.

11 SUÁREZ PANDIELLO (2008): 238-240. 
Al contrario de las declaraciones que aparecen en las Constituciones de otros países europeos, dado que Reino Unido carece de constitución escrita, no existe un reconocimiento expreso a la autonomía financiera de sus municipios. Este hecho pone de manifiesto que los tributos no son la pieza fundamental de la financiación local británica sino las transferencias (grants) procedentes del Estado. Esta dependencia financiera que existe respecto del Estado hace que la Hacienda local en materia de corresponsabilidad fiscal esté muy limitada en su autonomía.

Curiosamente, las restricciones a la autonomía no impiden que los municipios británicos asuman la responsabilidad en la gestión de competencias tales como la educación primaria y secundaria, las políticas de vivienda o los servicios sociales. Tal es así, que su actividad supone aproximadamente un $25 \%$ del gasto público ${ }^{12}$

Tras estas breves nociones introductorias, y antes de entrar al detalle en los tipos de ingresos, ya podemos intuir que estamos ante un modelo diferente al alemán. Un sistema de Hacienda local que refleja una concepción distinta respecto de los gobiernos locales que se constituyen más en gestores de servicios públicos que en entidades políticas de decisión a nivel municipal. Todo lo que se gana en eficiencia, pues los municipios se aproximan mucho a ser una prolongación del poder ejecutivo, se pierde en autonomía local, que no desaparece pero si está muy minorada.

\subsection{FUENTES DE INGRESOS LOCALES}

Para el análisis de la Hacienda británica hemos tomado el esquema planteado por VEGA BORREGO ${ }^{13}$, donde se examinan las distintas fuentes de financiación que componen el sistema destacando las características más relevantes de cada una de ellas en virtud del gasto al que atienden.

\section{A) FINANCIACIÓN DE GASTOS DE CAPITAL (Capital expenditure)}

Son gastos de capital los destinados a la financiación de las inversiones que realiza el Municipio y que se convierten en bienes de capital. El sufragio de estos gastos se sustenta en tres tipos de recursos que exponemos a continuación.

\section{A1. Operaciones de crédito (Borrowing)}

La regla general es que las operaciones de crédito pueden financiar gastos de inversión, sin embargo cabe la excepción de su empleo para subsanar problemas de tesorería mediante el endeudamiento transitorio.

Hasta el año $2003^{14}$ las operaciones de endeudamiento necesitaban el consentimiento previo del Estado. Tras la entrada en vigor de la nueva normativa local, el beneplácito previo sólo se exige para las operaciones en moneda distinta a la libra y el resto de operaciones no necesitan autorización. No obstante lo anterior, todas los endeudamientos están sujetos a unas reglas de prudencia (Prudential Code) que exige la intervención de un auditor externo a la entidad local quien determinará los limites hasta los que puede endeudarse un municipio. Además de esta premisa, el Estado también podrá limitar en cualquier momento las operaciones de crédito local en virtud de la coyuntura económica nacional.

\section{A2. Enajenación de bienes de capital (Capital receipts)}

La mencionada reforma de la financiación en 2003 también supuso la ampliación de los márgenes de uso de los ingresos obtenidos por las operaciones de venta de bienes de capital. Aún así, actualmente sigue limitado el destino de estos ingresos a la financiación del gasto corriente con el objetivo de evitar la descapitalización de la entidad local. En el marco de los límites vigentes, las enajenación de viviendas de propiedad pública por parte de una entidad local conlleva la participación del Estado en la plusvalía que genera (pooling system) dado que la construcción de las mismas se realiza con transferencias estatales.

12 ESPÓSITO (2004): 11

13 VEGA BORREGO (2010): 474 y ss. Reino Unido.

14 Fecha en la que entró en vigor el Local Government Act 2003, norma que regula la financiación de las Haciendas locales del 


\section{A3. Transferencias de capital (Capital Grants)}

Este tipo de ingresos, con origen en el Estado o en otras entidades que puedan financiar gastos de capital (Vg.: la Unión Europea), siempre se caracterizan por estar destinados a una finalidad de capital por lo tanto estamos ante transferencias condicionadas.

\section{B) FINANCIACIÓN DE GASTO CORRIENTE (Current expenditure)}

A diferencia de los anteriores, los gastos corrientes son los que afronta una entidad, en este caso local, con motivo de la prestación de los servicios que tiene atribuidos en competencia. La financiación de los mismos, al igual que con el gasto de capital, también depende en gran medida del Estado, aunque existe una parte que se cubre con una manifestación tributaria local. Pasamos a exponer los aspectos más relevantes de cara uno de ellos.

\section{B1. Sistema de transferencias (Grants)}

El conjunto de transferencias locales en Reino Unido es enredado. Apoyados en la clasificación de las transferencias establecida por ÁLVAREZ y CANTERO ${ }^{15}$ podemos dividirlas en dos tipos: incondicionales y condicionales, en función del fin al que se destinan. Así, las condicionales son aquellas donde el subvencionador ha establecido el propósito al que se debe destinar el ingreso, y las incondicionales son ingresos que no llevan un propósito obligado. A más abundamiento, desde la óptica de la autonomía que venimos analizando, las transferencias condicionadas reducen la expresión de la voluntad local a la mínima en tanto que ni tan siquiera permite al Municipio priorizar el destino del ingreso.

La evolución de las transferencias en la Hacienda local británica ha sido a favor del aumento de las subvenciones condicionadas y el detrimento de la transferencia sin condición, aunque el volumen de ingresos no ha variado en su conjunto, sólo se ha concretado en una reducción de la autonomía.

\section{a) Transferencia incondicionada (Fórmula grant o Revenue Support Grant)}

Bajo la denominación de este epígrafe se concentra la cesión principal que reciben las haciendas locales destinada a la financiación del gasto corriente sin quedar afectada a un servicio en particular. Su cálculo se realiza a través de un conjunto de variables objetivas ( $\mathrm{Vg}$.: población, territorio) que determinan la necesidad de financiación que soporta un municipio para prestar los servicios que no están costeados mediante subvención condicionada.

La determinación compete al Estado, y su cálculo se resume de la siguiente manera:

«la transferencia general es el resultado de restar al coste teórico de los servicios de una entidad su capacidad fiscal teórica, materializada en el council tax. A este resultado se le adiciona una suma fija (Central Allocation), dando lugar a una cifra que debe compararse con la del ejercicio anterior a efectos de determinar si debe o no incrementarse la misma, para garantizar el porcentaje de incremento mínimo que se haya establecido (Floor Damping Block) ${ }^{16} . »$

Una vez recibida la cantidad por la entidad local, ésta decidirá bajo su autonomía cómo distribuirla entre los diferentes servicios que financia según las prioridades del gobierno local.

\section{b) Transferencias condicionadas (specific grants)}

Ya definidas al comienzo de este epígrafe, la característica fundamental es su destino condicionado a los gastos ocasionados por un servicio determinado. A pesar de la variedad que existe, destacamos entre todas la transferencia que reciben los municipios destinada a sufragar las competencias educativas (Dedicated schools grant) en tanto que es la más importante por su cuantía junto con la transferencia general.

15 ÁLVAREZ GARCÍA y CANTERO PRIETO (2008): 141.

16 VEGA BORREGO (2010): 486. 
Cabe señalar dos apuntes sobre el funcionamiento de estas transferencias. Primeramente destacar que las transferencias tienen una mecánica de vasos comunicantes, esto es todo servicio que pasa a ser subvencionado por una transferencia condicional deja de computar en la transferencia general y viceversa. La segunda idea incide en el papel limitado que otorga este tipo de transferencias a la autonomía financiera dado que el Municipio se convierte en mero gestor sin capacidad de decisión en el origen o en el destino del ingreso.

\section{B2. Impuestos: Council Tax}

La única manifestación impositiva de los municipios británicos es el council tax; es una figura tributaria híbrida entre un impuesto sobre la propiedad inmobiliaria residencia y una tasa forzosa sobre los habitantes de una entidad local con el fin de contribuir a financiar los servicios que en ella reciben ${ }^{17}$. Este impuesto apareció en el año 1993 en sustitución del poll tax ${ }^{18}$ y es de naturaleza impositiva en tanto que viene impuesto por ley sin necesidad de que se realice ninguna actividad específica de la Administración a favor del ciudadano.

El Estado determinará para este impuesto varios elementos fundamentales. Por una parte la base imponible, que es el valor del inmueble, será calculado por un órgano estatal (Valuation Office Agency) a través de parámetros similares a los utilizados en España para las valoraciones catastrales ( $V g$.: localización, superficie). Por otra parte los tramos de valor de la propiedad, horquilla donde las viviendas contenidas tributan igual, y las ratios de cuota de dichos tramos que estarán en función de la cuota marcada por el Municipio para el tramo «D». Por lo tanto, a la entidad local normativamente le corresponde fijar la cuota del council tax en un tramo y el resto de tramos se calcularán automáticamente en virtud de los ratios establecidos. No obstante lo anterior, cabe señalar que la autonomía en esta decisión municipal siempre quedará acotada directamente en virtud de los techos definitivos que establezca el Gobierno central, e indirectamente también se puede ver forzado el Municipio a incrementar la presión fiscal para subsanar los desajustes y carencias que se generen en el sistema de transferencias.

Aunque este impuesto tiene un papel relevante en el sistema de financiación de los municipios en Reino Unido, su posición es claramente inferior a la que presentan las transferencias. Sin embargo, es la única herramienta de que disponen las entidades locales para conseguir financiación bajo su autonomía y sin depender de las decisiones del Estado. El problema es de presión fiscal, pues al no contar con otro tipo de impuestos, cada necesidad adicional de gasto siempre supondrá un aumento de la cuota del council tax sobre las mismas personas.

\section{B3. Tasas (Fees and charges)}

Desde el Local Government Act de 2003 las Entidades locales pueden ejercer la potestad de crear tasas por la prestación de cualquier servicio municipal salvo la educación, la seguridad ciudadana, la extinción de incendios, las elecciones y el préstamo de libros en bibliotecas públicas ${ }^{19}$. Por lo tanto nos encontramos, junto con el coucil tax, ante el otro instrumento de autonomía de la Hacienda local.

Aunque la aplicación no es homogénea en todos los municipios, la tendencia al establecimiento de tasas en concepto de servicios municipales por parte ha ido en aumento. Son tres los motivos que han inducido este crecimiento ${ }^{20}: 1$ ) reducir la presión fiscal del council tax pasando a trasladar el coste de determinados servicios sólo a los receptores de los mismos y no al conjunto de los contribuyentes; 2) los ingresos por tasas no computan a la hora de calcular la transferencia general, cosa que si ocurre con el impuesto; 3) las tasas británicas, a diferencia de España, no cuentan con techos en virtud del coste del servicio.

\section{VALORACIÓN A LA LUZ DEL SISTEMA ESPAÑOL}

La herramienta comparativa nos arroja como primera evidencia el elemento común entre los países confrontados y España: el reconocimiento de la autonomía local. Cierto es que mientras en Alemania, quizás por

17 VEGA BORREGO (2010): 476.

18 El poll tax era un impuesto que gravaba a los adultos residentes en una entidad local con una cantidad fija, independientemente de criterios como renta o patrimonio, bajo la idea de pagar una cantidad por los servicios que recibía en esa localidad.

19 ESPÓSITO (2004): 46.

20 VEGA BORREGO (2010): 493. 
la realidad federal, los municipios han alcanzado un alto grado de corresponsabilidad fiscal, en Reino Unido las haciendas locales dependen en un alto grado de las transferencias que les envía el Gobierno central. Si tuviéramos que posicionar a España, claramente el grado de autonomía local se acercaría más al nivel alcanzado en Alemania.

Ahora bien, como hemos podido comprobar en el análisis de las fuentes de financiación municipal en cada país, el reconocimiento de autonomía local no es sinónimo de autonomía tributaria y mucho menos de suficiencia financiera. Tanto en los países estudiados como en España, la participación del Estado es fundamental en cada una de las herramientas que componen la financiación. Así, la potestad fiscal municipal siempre tiene su origen en una ley estatal que enmarca las competencias del Municipio y, siempre que sea necesario, se podrá limitar su margen de actuación. Por otra parte, las transferencias o compensaciones que recibe el Municipio suelen tener un origen condicionado, una finalidad restringida o ambas cosas. Este conjunto de restricciones se podría entender como un callejón sin salidas para la autonomía local, sin embargo no debiera ser esta nuestra conclusión. Las limitaciones en cada uno de los países, también en España, son una consecuencia lógica de la estructura funcional del estado, y suponen una tensión necesaria en cuanto a lo que tienen de reto para los municipios en su afán de acercar su realidad competencial a su situación financiera.

El objetivo de la correcta financiación municipal, en nuestro caso la tan traída reforma de las haciendas locales en España, es una constante en todos los sistemas y, a diferencia de España, vemos cómo se han dado pasos en algunos países. El caso de Reino Unido es significativo porque el Estado, aunque no ha consentido aumentar la capacidad de decisión de los municipios sobre los impuestos, ha permitido sin embargo el establecimiento de tasas por prestación de servicios sin constituir ningún techo de ingresos, cosa que sí sucede en España. La Hacienda local británica muestra cómo se pueden instar reformas encaminadas a la suficiencia financiera sin necesidad de aumentar la autonomía fiscal, especialmente en materia de impuestos en tanto que son obligaciones que inciden sensiblemente y sin beneficio directo sobre el contribuyente.

Al igual que Reino Unido, Alemania también está dando pasos en materia de reforma de la Hacienda local. Sin embargo, el estado federal ha optado por incrementar la autonomía fiscal a través de la participación de los municipios en impuestos de corte estatal o federal como son el IRPF o el IVA. Frente a la situación que actualmente se da en la Hacienda local española, es destacable cómo en Alemania se ha conseguido de manera estable y eficaz compensar a los entes locales por la disminución de ingresos tras las limitaciones aplicadas al Impuestos sobre Actividades Económicas. Desde posiciones centralistas se atacaría este ánimo de hacer corresponsables a los municipios en la gestión de estos impuestos; sin embargo consideramos que en los Estados donde se ha optado por una organización descentralizada, esta concepción debe aplicarse en todos los ámbitos con el fin de evitar incoherencias y poder determinar las esferas de responsabilidad a la par que la financiación.

En otro orden de cosas, descubrimos cómo el marco de competencias y servicios que tiene atribuido el Municipio debe siempre establecer la pauta para ordenar la financiación. Observando el sistema británico vemos como las transferencias se articulan, directa o indirectamente, en función de los servicios a los que se destinan. Igual ocurren en Alemania donde la participación en los impuestos viene en proporción al conjunto de servicios que prestan al contribuyente. En contraste con lo anterior, en España resulta evidente la necesidad de reformar la financiación local a la vista de la reestructuración competencial tras la Ley 27/2013, de 27 de diciembre, de racionalización y sostenibilidad de la Administración Local, y tras haber sido declarado inconstitucional y nulo el art. 57 bis, relativo a la garantía de pago en el ejercicio de competencias delegadas, por Sentencia TC (Pleno) 41/2016, de 3 de marzo (BOE, 8 abril). La única herramienta que se estableció para conseguir ajustar parte de este desequilibrio fue declarada inconstitucional por una cuestión de forma. En definitiva, los recursos deben estar en proporción al volumen de servicios prestados, de lo contrario estamos ante un sistema de servicios municipales precario en sus recursos, inestable en sus prestaciones e incoherente en sus principios; cosas todas ellas que repercuten negativamente en los ciudadanos. España tiene pendiente este reto.

Finalmente queremos destacar la existencia de mecanismos de compensación entre las distintas haciendas locales en los diferentes estados analizados. Aunque las herramientas utilizadas son diversas ( $\mathrm{Vg}$.: coeficientes correctores, ratios y límites) todas consiguen compensar, al menos en lo que se refiere a servicios básicos, las desigualdades territoriales. Así, ante sistemas diferentes, detectamos cómo la compensación entre municipios debe ser articulada también desde el Estado en tanto que es garante no sólo de la autonomía local sino también de la solidaridad tributaria. A nuestro juicio, esta premisa debe prevalecer en cada reforma que se practique al sistema de financiación local. 
REALA. Nueva Época - N. 7 , mayo 2017 - ISSN: 1989-8975 - DOI: 10.24965/reala.v0i7.10396 - [Págs. 115-125]

Enfoque de la autonomía local en los sistemas alemán y británico de financiación municipal

Francisco Javier Durán García

\section{BIBLIOGRAFÍA}

ÁLVAREZ GARCÍA, Santiago y CANTERO PRIETO, David (2008): "Las transferencias en la financiación municipal. Una comparación internacional”, Papeles de Economía Española, núm. 115.

DE LA FUENTE, Ángel (2017): “La financiación regional en Alemania y en España: Una perspectiva comparada”, Fedea Policy Papers, núm. 01.

ESPÓSITO, T. (2004): "England's System of Local Government Finance”, Policy Exchange, London.

GARCÍA FRÍAS, Ángel (2005): "Análisis de la financiación de los municipios en Alemania", en CASADO OLLERO, Gabriel (coord.): La financiación de los Municipios, experiencias comparadas. Dykinson, S. L., Madrid.

GARCÍA MARTÍNEZ, Andrés (2009): "La participación de los municipios alemanes en el impuesto sobre la renta", Revista d'Estudis Autonòmics i Federals (REAF), núm. 9, Barcelona.

SUÁREZ PANDIELLO, Javier, coord. (2008): La financiación local en España: radiografía del presente y propuestas de futuro. Gráficas Varona, S. A., Salamanca.

VEGA BORREGO, Félix Alberto (2010): "Financiación de los entes locales en Reino Unido", en VELASCO CABALLERO, Francisco: Gobiernos locales en Estados federales y descentralizados: Alemania, Italia y Reino Unido. Institut d'Estudis Autonòmics, Generalitat de Catalunya, Barcelona.

VELASCO CABALLERO, Francisco (2010): Gobiernos locales en Estados federales y descentralizados: Alemania, Italia y Reino Unido. Institut d'Estudis Autonòmics, Generalitat de Catalunya, Barcelona. 